Original Article

\title{
Diversity and regularity in infant crawling with typical development
}

\author{
Shimpei Yamamoto, RPT ${ }^{1)^{*}}$, Lee Yonghi, MSc, RPT ${ }^{1)}$, Umi Matsumura, MSc, RPT ${ }^{1)}$, \\ TOSHIYA TSURUSAKI, PhD, RPT ${ }^{2}$ \\ 1) Health Sciences, Nagasaki University Graduate School of Biomedical Sciences: 1-7-1 Sakamoto, \\ Nagasaki 852-8520, Japan \\ 2) Institute of Biomedical Sciences, Nagasaki University, Japan
}

\begin{abstract}
Purpose] The purpose of this longitudinal study was to investigate the diversity in infant crawling and examine the quantitative regularity in crawling variations necessary for the acquisition of walking in infants with typical development. [Participants and Methods] Infants with no neurological or orthopedic problems participated in this study. Using Internet Protocol (IP) cameras, crawling was simultaneously filmed from six different angles. Filming was continued until the acquisition of independent walking. The crawling movement in the video was coded. We considered the number of different completed codes as the number of variations and examined the cumulative number during the filming period in each participant. [Results] Nineteen infants completed the study. The pattern of change in the cumulative number of variations with increasing age (in days) varied between cases. Although the cumulative number of crawling variations at the time of acquisition of independent walking was inconsistent, it was negatively correlated with the crawling start age (in days). [Conclusion] Diversity exists in infant crawling. Infants who start crawling at a younger age tend to express more variation, whereas infants who start crawling when older tend to express less variation.

Key words: Crawling, Motor development, Variation
\end{abstract}

(This article was submitted Mar. 9, 2019, and was accepted May 4, 2020)

\section{INTRODUCTION}

The development of neural networks requires not only the proliferation of some neural elements, but also substantial loss of other neural elements. This regressive process (loss of neural elements) includes synaptic exuberance and pruning in which there is massive excess production of connections followed by the systematic elimination of up to $50 \%$ of those connections, mainly postnatally ${ }^{1)}$. Studies of both monkeys and humans have documented widespread exuberant production of connections throughout all brain regions in the early postnatal period ${ }^{2-6)}$. After this huge production, unnecessary cells and connections are removed by cell death and synaptic pruning across the period of childhood and adolescence ${ }^{7)}$. These observations are consistent with ample histological evidence for reduction of synaptic density in the cortex during childhood ${ }^{6}$. Many factors affect the elimination of pathways. Importantly, afferent input plays a critical role in modulating the stabilization or elimination of pathways ${ }^{1}$. On the other hand, as one feature of brain development, dendrites and spines show remarkable plasticity in response to experience and can form synapses in hours and possibly even minutes after some experiences ${ }^{7}$.

According to the Neuronal Group Selection Theory (NGST), brain systems are dynamically organized into variable networks, the structure and function of which are selected by development and behavior ${ }^{8}$. In summary, the changes in neural network, that is the pruning and production of neurons, and furthermore human development, depends on environmental factors as well as genetic ones. Therefore, the varied nature of the nervous system and its continuous interaction with varied

*Corresponding author. Shimpei Yamamoto (E-mail: bb55219017@ms.nagasaki-u.ac.jp)

(C2020 The Society of Physical Therapy Science. Published by IPEC Inc.

(c) (1) $\odot$ This is an open-access article distributed under the terms of the Creative Commons Attribution Non-Commercial No DerivaCC BY NC ND tives (by-nc-nd) License. (CC-BY-NC-ND 4.0: https://creativecommons.org/licenses/by-nc-nd/4.0/) 
environments, gives rise to abundant diversity in the way motor development presents in individual children ${ }^{9)}$. And in this theory, typical motor development shows variation and adaptive variability. Variation means the presence and expression of a broad repertoire of behaviors for a specific motor function. Variability denotes the capacity to select from the repertoire the motor strategy that fits the situation best ${ }^{10)}$.

On the other hand, atypical motor development is characterized by limitations in variation and variability. For example, infants who are at risk for cerebral palsy (CP) show abnormal general movements (GMs), which are characterized by a severely reduced movement complexity and variation ${ }^{10,11)}$. In addition, the consistent presence of definitely abnormal GMs during the first postnatal months is associated with a very high risk for the development of $\mathrm{CP}^{11,12)}$. Hadders-Algra stated that variation (the evaluation of the size of the repertoire) was a parameter that may be applied in the phase of variability ${ }^{10)}$. Therefore, it is important for infants to be assessed developmental condition from the perspective of variation.

Crawling (including hands-and-knees, belly crawling, bear crawling) is often regarded as one of the motor milestones in infant motor development, and is known to have positive effects on an infant's development in terms of various functions. Crawling facilitates the development of sensory and motor systems of the body and later motor skill development ${ }^{13)}$. It has also been shown that the longer the period an infant crawls the higher the ability to perceive space and to search for objects ${ }^{14)}$. Moreover, McEwan et al. indicated that the process of crawling provides a state of eye-hand coordination, vestibular processing, improvement of balance and social maturation ${ }^{13}$. Crawling therefore has important roles in infant development, as infants learn how to move their bodies for walking through crawling movements.

To our knowledge, there has been no previous research on crawling in terms of variation and variability. Thus, we aimed to examine the features of variation in crawling with typical development. In this study, we made two hypotheses that 1) diversity exists in typical developmental crawling, and 2) there is a quantitative regularity in the number of crawling variations that are necessary for the acquisition of independent walking between infants with typical development, and examined them.

\section{PARTICIPANTS AND METHODS}

The design of this study was longitudinal. We requested two nurseries to cooperate with this study and recruited infants who belonged to the facilities. Forty infants who did not have any diagnosis at the time (with no neurological or orthopedic problems), and were born at full-term (37 to 41 weeks), participated in this study. Due to lack of data as a result of changing nurseries, poor physical condition and no crawling (moving with sitting), we excluded twenty-one infants, and finally targeted nineteen residual infants for analysis (Fig. 1). These consisted of 13 males and 6 females. Written informed consent was obtained after the contents of the explanation have been well understood by each infant's parent.

Using 6 IP cameras (Qwatch TS-WLCAM, IODATA), the crawling was filmed simultaneously from the front, back, left, right, and top ( 2 directions). The filming was performed inside the facilities at intervals of 1 to 2 weeks and continued from the time the consent for participation in the study was obtained (almost the same as the time crawling started) until the acquisition of independent walking. We regarded the point in time when most of locomotion in nursery shifted to walking independently,

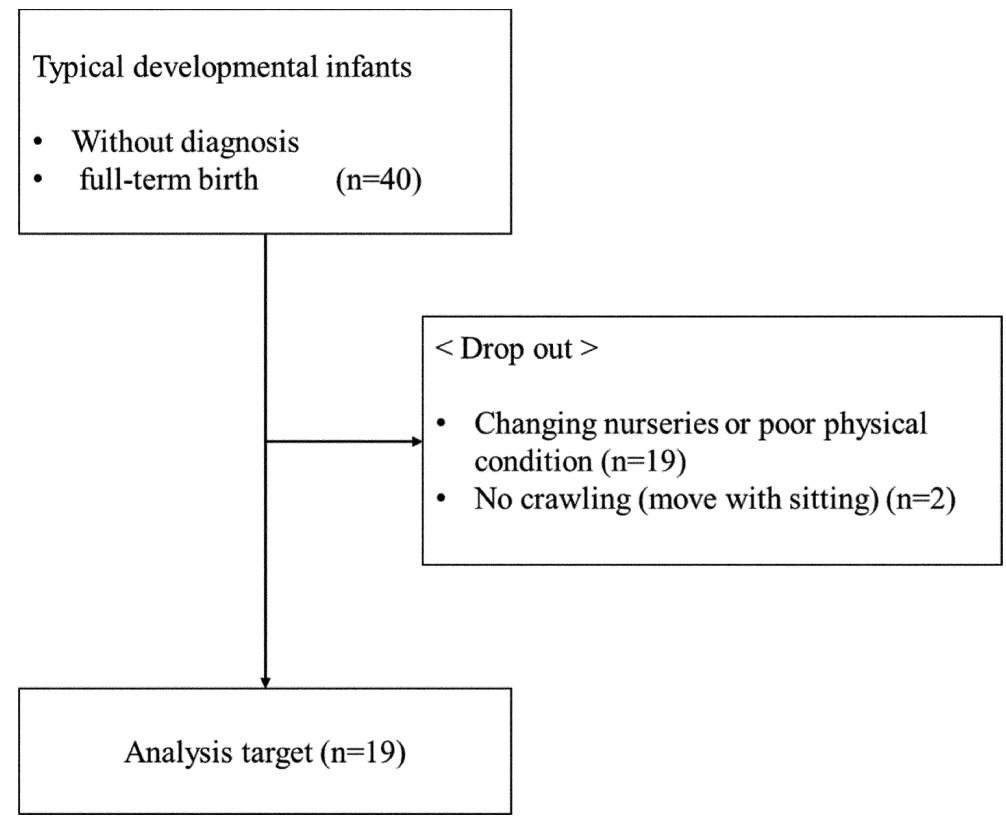

Fig. 1. Flow-chart of study participants. 
as the acquisition of independent walking. This point was judged by physical therapists and nursery teachers. One cycle of crawling was defined as the interval between the left (or right) upper limb leaving the floor and the trunk moving until the left (or right) upper limb leaves the floor again. Approximately 10 cycles were recorded at each filming episode. The crawling movement in the video was coded objectively using "Crawling Behavior Analysis Criteria"15, 16) by physical therapists. At each cycle, the movements observed in each segment (neck, trunk, upper limb, and lower limb) were digitized according to the criteria. For example, if weight-bearing by right upper limb was support with hand, we numbered " 1 ", and if support with forearm, we numbered " 2 ". There were twenty-four items such as above in the criteria, and the twenty-four numerical values that were numbered at each item were combined into one to code the whole bodies movement. We considered the number of types of completed codes (twenty-four digits) as the number of variations, and examined the cumulative number of variations throughout the filming period in individuals.

All data were analyzed with JMP Pro. Independent t-test was used to examine the differences of the developmental data between male and female groups. Pearson correlation coefficient was used to examine some relationships between the cumulative number of crawling variations and the other variables such as age at crawling, duration of crawling and age at independent walking, and $\mathrm{p}<0.05$ was considered statistically significant. This study was approved by the Ethics Committee of the Graduate School of Medical Facilities, Nagasaki University (Approved number 18061431).

\section{RESULTS}

The developmental data of each case are shown in Table 1. The mean (SD) age in days at start of crawling was 272 (46), filming period 145 (39) days, and this number represented the mean duration of crawling in infants. The mean (SD) age in days of acquisition of independent walking was 417 (42), and the cumulative number of crawling variations at independent walking 43 (12) (Table 1). In Table 2, none of age at crawling, duration of crawling, age at independent walking and cumulative number of crawling variations showed any significant differences between male and female groups.

The pattern of changes in the cumulative number of variations with increasing age in days varied between the cases and varied depending on the infant (Fig. 2).

The cumulative number of crawling variations at the time of the acquisition of independent walking was 23 at the minimum and 65 at the maximum (Table 1), and there was no consistency. On the other hand, when considering the age in days as shown in Fig. 2, infants who started crawling at an earlier age tended to have a larger cumulative number of variations (such as case B, D, H, I, J, etc.), and infants who started crawling at later age tended to have a smaller cumulative number of

Table 1. Data of each case

\begin{tabular}{|c|c|c|c|c|c|}
\hline Case No. (gender) & $\begin{array}{l}\text { Age at } \\
\text { crawling } \\
\text { (days) }\end{array}$ & $\begin{array}{c}\text { Duration of } \\
\text { crawling } \\
\text { (days) }\end{array}$ & $\begin{array}{c}\text { Age at independent } \\
\text { walking } \\
\text { (days) }\end{array}$ & $\begin{array}{c}\text { Number of videos } \\
\text { taken }\end{array}$ & $\begin{array}{c}\text { Cumulative } \\
\text { number of crawling } \\
\text { variations }\end{array}$ \\
\hline Case A (m) & 251 & 174 & 425 & 11 & 45 \\
\hline Case B (m) & 245 & 141 & 386 & 13 & 49 \\
\hline Case C (m) & 363 & 127 & 490 & 9 & 31 \\
\hline Case D (m) & 266 & 156 & 422 & 15 & 59 \\
\hline Case E (f) & 267 & 154 & 421 & 10 & 38 \\
\hline Case F (f) & 286 & 106 & 392 & 8 & 26 \\
\hline Case G (f) & 284 & 166 & 450 & 11 & 46 \\
\hline Case H (f) & 250 & 166 & 416 & 12 & 48 \\
\hline Case I (f) & 228 & 175 & 403 & 15 & 49 \\
\hline Case J (m) & 219 & 144 & 363 & 13 & 54 \\
\hline Case K (m) & 197 & 128 & 325 & 15 & 42 \\
\hline Case L (m) & 226 & 161 & 387 & 16 & 63 \\
\hline Case M (m) & 267 & 98 & 365 & 11 & 39 \\
\hline Case N (m) & 263 & 217 & 480 & 21 & 38 \\
\hline Case O (f) & 361 & 66 & 427 & 10 & 32 \\
\hline Case P (m) & 285 & 147 & 432 & 13 & 65 \\
\hline Case Q (m) & 318 & 91 & 409 & 9 & 38 \\
\hline Case R (m) & 253 & 212 & 465 & 19 & 30 \\
\hline Case S (m) & 341 & 119 & 460 & 13 & 23 \\
\hline Mean & 272.1 & 144.6 & 416.7 & 12.8 & 42.9 \\
\hline $\mathrm{SD}$ & 46.1 & 38.7 & 42.0 & 3.4 & 12.0 \\
\hline
\end{tabular}

SD: standard deviation. 
Table 2. Differences in gender on each data

\begin{tabular}{lcccc}
\hline & Male $(\mathrm{n}=13)$ & Female $(\mathrm{n}=6)$ & \multicolumn{2}{c}{ Comparison } \\
\cline { 2 - 4 } & Mean (SD) & Mean (SD) & t-value & p-value \\
\hline Age at crawling & $268(47)$ & $279(45)$ & -0.453 & 0.655 \\
Duration of crawling & $147(38)$ & $138(43)$ & 0.433 & 0.67 \\
Age at independent walking & $416(49)$ & $418(20)$ & -0.097 & 0.923 \\
Cumulative number of crawling variations & $44(13)$ & $40(9)$ & 0.747 & 0.465 \\
\hline
\end{tabular}

SD: standard deviation; p: probability.

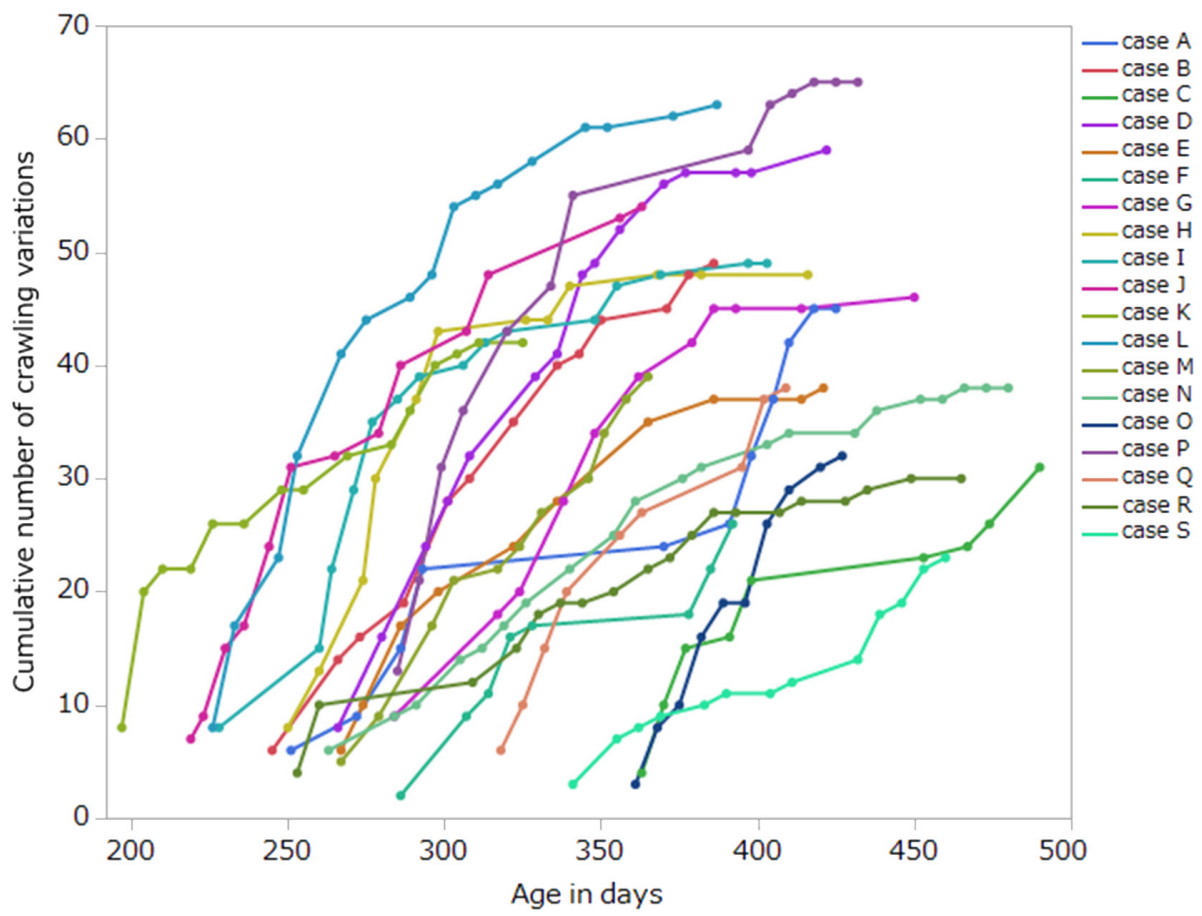

Fig. 2. Changes in the cumulative number of crawling variations with increasing age in days.

Table 3. Correlation of cumulative number of crawling variations

\begin{tabular}{lcccc}
\hline & $\begin{array}{c}\text { Cumulative number of } \\
\text { crawling variations }\end{array}$ & $\begin{array}{c}\text { Age at crawling } \\
\text { (days) }\end{array}$ & $\begin{array}{c}\text { Duration of crawl- } \\
\text { ing (days) }\end{array}$ & $\begin{array}{c}\text { Age at independent } \\
\text { walking (days) }\end{array}$ \\
\hline Cumulative number of crawling variations & 1 & & & \\
Age at crawling (days) & $-0.54^{*}$ & 1 & 1 & \\
Duration of crawling (days) & 0.28 & $-0.52^{*}$ & 0.35 & 1 \\
Age at independent walking (days) & -0.33 & $0.62^{* *}$ & 0.35 \\
\hline
\end{tabular}

$* \mathrm{p}<0.05,{ }^{* *} \mathrm{p}<0.01$. Pearson correlation.

variations (such as case A, C, E, F, G, etc.). There was a statistically significant correlation between the crawling start age in days and the cumulative number of variations (Pearson correlation coefficient, $r=-0.54 ; p<0.05$ ) (Table 3).

\section{DISCUSSION}

This longitudinal study examined the diversity in crawling, and the quantitative regularity in crawling variation in infants with typical development. The key outcome measure was the cumulative number of crawling variations. Our results showed diversity in variations between infants. Although the quantity of crawling variation showed no consistency in infants, there was a relationship between the quantity of crawling variation and the age at crawling. 
In this study, the maximum age in days at the time of acquiring of independent walking was 490 (case C), which was almost the same as that of general typically developing infants ${ }^{17)}$. It is therefore considered that all the recruited infants lack any delay in motor development at this time.

In Fig. 2, the changes in the cumulative number of variations with increasing age in days was different by the cases, and both the age at crawling and the period of crawling also varied depending on the infant. This result showed that each infant expressed the various combinations of body movements with various time and different rate of change, which were unique to individual. Motor development is a non-linear process with phases of transition, affected by many factors. The factors consist of the features of the child itself, such as body weight, muscle power and components of the environment, such as housing conditions, the composition of the family, and the presence of toys ${ }^{9)}$. As mentioned above, the various changes in quantitative variation shown in our results may be attributed to variations in intrinsic and environmental factors between the individuals. Therefore, we concluded that this result indicated diversity in infant crawling.

Additionally, it is obvious that infants were generating and selecting new or efficient movements through the trial-anderror experiences of crawling, as all the cases in Fig. 1 showed the increase of cumulative number of crawling variations.

The cumulative number of crawling variations at the time of the acquisition of independent walking had a large range of data, with 23 at the minimum and 65 at the maximum (Table 1), and with no consistency. This result showed that the number of crawling variations differed in infants with typical development. On the other hand, when all cases were arranged on the same age axis as shown in Fig. 2, there seemed to be some tendency such as below. Infants who started crawling at earlier ages in days had larger cumulative number of variations (case B, D, H, I, J, etc.), and infants who started crawling at later age in days had smaller cumulative number of variations (case A, C, E, F, G, etc.). Table 3 also shows the results of Pearson correlation coefficient between the cumulative number of crawling variations and the other variables. The negative correlation between the crawling start age in days and the cumulative number of variations $(r=-0.54 ; \mathrm{p}<0.05)$ supports that tendency. Besides, because there was not statistically significant correlation between the duration of crawling and the cumulative number of variations, it seemed that infants who started crawling earlier tended to express more variation especially in earlier days after beginning of crawling, with unaffected by the length of the crawling period. Certainly, the cases with earlier start and more variation (such as case B, D, H, I, J) showed the rapidly increases of cumulative number of variations in early days after beginning of crawling in Fig. 2. Thus, it is considered that infants who start crawling earlier are trying more types of the body movements than infants who start crawling later. According to NGST, motor development is characterized by 2 phases of variability: primary and secondary ${ }^{18,19)}$. During the phase of primary variability, motor behavior is characterized by abundant variation. The variation is induced by explorative activity of the nervous system. When switching from primary to secondary variability, the nervous system begins to use the afferent information produced by behavior and experience for selection of the motor behavior that fits the situation best. The process of selection, which is characteristic of the phase of secondary variability, is based on active trial-and-error experiences that are unique to the individual ${ }^{20-22)}$. Accordingly, it is conceivable that the background of that tendency in infants shown in Fig. 2 includes some factors of these variabilities which each infant has.

As all the cases in this study acquired independent walking finally, the contents of crawling variation observed commonly in all the cases may represent the contents of crawling variations necessary for the acquisition of independent walking. The contents of these variations observed in this study have however, yet to be analyzed. In recent years, it has been reported that activity in the prone position termed "Tummy Time" is important for infant development and head shape ${ }^{23-25)}$. Tummy time, defined as an infant being placed on their stomach whilst awake and supervised, provides an opportunity for the infant to stimulate and enhance their motor development ${ }^{23)}$. Evidence is also accumulating that early implementation of tummy time is effective in reducing motor delay in young infants with Down syndrome ${ }^{26}$. Previous studies have examined the duration and timing of Tummy Time ${ }^{27-29)}$. However, evidence for the activity contents of Tummy Time is inadequate. It is anticipated that our study, most likely the contents of crawling variation in typical development, may compensate for this disadvantage if we could find some commonalities in the contents of crawling variation that seem necessary for typical motor development and could apply those contents to the activity contents of Tummy Time. Thus, it needs to be examined, and we will tackle with the qualitative research on crawling variation in the future. In addition, as a future prospect, we need to follow up the infants recruited in this study to investigate how the differences in crawling variation or age at crawling shown in this study will affect the order of motor development when they are 3 and 5 years old.

There were several limitations to this study. First, the number of participants was limited. Second, in order to reproduce the actual crawling period, we attempted to begin filming as much as possible from the start of the crawling period, but the slight gaps were inevitable. It is necessary to improve these limitations.

In conclusion with respect to the present study, it is suggested that there is diversity in infants crawling and that there is a relationship between the start of the crawling stage and the quantity of crawling variation.

\section{Funding}

This work was supported by JSPS KAKENHI Grant Number JP18K02444.

\section{Conflict of interest}

There is no conflict in this research. 


\section{REFERENCES}

1) Stiles J, Jernigan TL: The basics of brain development. Neuropsychol Rev, 2010, 20: 327-348. [Medline] [CrossRef]

2) Zecevic N, Bourgeois JP, Rakic P: Changes in synaptic density in motor cortex of rhesus monkey during fetal and postnatal life. Brain Res Dev Brain Res, 1989, 50: 11-32. [Medline] [CrossRef]

3) Bourgeois JP, Rakic P: Changes of synaptic density in the primary visual cortex of the macaque monkey from fetal to adult stage. J Neurosci, 1993, 13: 2801-2820. [Medline] [CrossRef]

4) Bourgeois JP, Goldman-Rakic PS, Rakic P: Synaptogenesis in the prefrontal cortex of rhesus monkeys. Cereb Cortex, 1994, 4: 78-96. [Medline] [CrossRef]

5) Huttenlocher PR, de Courten C: The development of synapses in striate cortex of man. Hum Neurobiol, 1987, 6: 1-9. [Medline]

6) Huttenlocher PR, Dabholkar AS: Regional differences in synaptogenesis in human cerebral cortex. J Comp Neurol, 1997, 387: 167-178. [Medline] [CrossRef]

7) Greenough WT, Chang FF: Plasticity of synapse structure and pattern in the cerebral cortex. Cereb Cortex, 1989, 7: 391-440. [CrossRef]

8) Hadders-Algra M: The neuronal group selection theory: promising principles for understanding and treating developmental motor disorders. Dev Med Child Neurol, 2000, 42: 707-715. [Medline] [CrossRef]

9) Hadders-Algra M: Early human motor development: from variation to the ability to vary and adapt. Neurosci Biobehav Rev, 2018, 90: 411-427. [Medline] [CrossRef]

10) Hadders-Algra M: Variation and variability: key words in human motor development. Phys Ther, 2010, 90: 1823-1837. [Medline] [CrossRef]

11) Hadders-Algra M: General movements: a window for early identification of children at high risk for developmental disorders. J Pediatr, 2004 , 145: S12-S18. [Medline] [CrossRef]

12) Einspieler C, Prechtl HF, Ferrari F, et al.: The qualitative assessment of general movements in preterm, term and young infants--review of the methodology. Early Hum Dev, 1997, 50: 47-60. [Medline] [CrossRef]

13) McEwan MH, Dihoff RE, Brosvic GM: Early infant crawling experience is reflected in later motor skill development. Percept Mot Skills, 1991, 72: 75-79. [Medline] [CrossRef]

14) Bell MA, Fox NA: Individual differences in object permanence performance at 8 months: locomotor experience and brain electrical activity. Dev Psychobiol, 1997, 31: 287-297. [Medline] [CrossRef]

15) Tsurusaki T: http://www2.am.nagasaki-u.ac.jp/ptd/tsurusaki/3igenond/7.html (Accessed Jun. 17, 2020)

16) Tsurusaki T, Terao H: Validation of the reliability of the criteria for crawling motion analysis. Rigakuryoho Kagaku, 2017, 32: 323-328. [CrossRef]

17) WHO Multicentre Growth Reference Study Group: WHO Motor Development Study: windows of achievement for six gross motor development milestones. Acta Paediatr Suppl, 2006, 450: 86-95. [Medline]

18) Edelman GM: Neural Darwinism: the theory of neuronal group selection. Artif Intell, 1989, 39: 121-136. [CrossRef]

19) Edelman GM: Neural Darwinism: selection and reentrant signaling in higher brain function. Neuron, 1993, 10: 115-125. [Medline] [CrossRef]

20) Greenough WT, Black JE, Wallace CS: Experience and brain development. Child Dev, 1987, 58: 539-559. [Medline] [CrossRef]

21) Hadders-Algra M, Brogren E, Forssberg H: Training affects the development of postural adjustments in sitting infants. J Physiol, 1996, 493: 289-298. [Medline] [CrossRef]

22) Graybiel AM: The basal ganglia: learning new tricks and loving it. Curr Opin Neurobiol, 2005, 15: 638-644. [Medline] [CrossRef]

23) Kuo YL, Liao HF, Chen PC, et al.: The influence of wakeful prone positioning on motor development during the early life. J Dev Behav Pediatr, 2008, 29: 367-376. [Medline] [CrossRef]

24) Hewitt L, Stanley RM, Okely AD: Correlates of tummy time in infants aged 0-12 months old: a systematic review. Infant Behav Dev, 2017, 49: 310-321. [Medline] [CrossRef]

25) Russell DC, Kriel H, Joubert G, et al.: Prone positioning and motor development in the first 6 weeks of life. S Afr J Occup Ther, $2009,39: 11-14$.

26) Wentz EE: Importance of initiating a "tummy time" intervention early in infants with Down syndrome. Pediatr Phys Ther, 2017, 29: 68-75. [Medline] [CrossRef]

27) Dudek-Shriber L, Zelazny S: The effects of prone positioning on the quality and acquisition of developmental milestones in four-month-old infants. Pediatr Phys Ther, 2007, 19: 48-55. [Medline] [CrossRef]

28) Majnemer A, Barr RG: Association between sleep position and early motor development. J Pediatr, 2006, 149: 623-629. [Medline] [CrossRef]

29) Davis BE, Moon RY, Sachs HC, et al.: Effects of sleep position on infant motor development. Pediatrics, 1998, 102: 1135-1140. [Medline] [CrossRef] 